\title{
Condition Assessment of Low Voltage Photovoltaic DC Cables under Thermal Stress Using Non-Destructive Electrical Techniques
}

\author{
Ehtasham Mustafa ${ }^{1}\left[\right.$ [ Ramy S. A. Afia ${ }^{1,2} \cdot$ Zoltán Ádám Tamus $^{1}$
}

Received: 17 November 2019 / Revised: 6 April 2020 / Accepted: 30 April 2020 / Published online: 15 May 2020

(c) The Author(s) 2020

\begin{abstract}
The output power of the photovoltaic system is heavily dependent on the low voltage (LV) DC cables which are exposed to multiple stresses such as climatic, mechanical, electrical, and thermal stress, hence makes them more exposed to aging as compared to other components in the system. Accordingly, it is essential to monitor the state and know the real cause of the insulation degradation of the cable. The physio-chemical changes inside the insulation during service is attributed to the thermal stress, which the cable has to endure constantly. Traditionally, destructive test techniques have been adopted to study the aging phenomenon in the cable insulation, making them unsuitable for on-line condition monitoring. This research work has been aimed to study the degradation in LV photovoltaic DC cables under thermal stress by measuring the dielectric properties; complex permittivity, $\tan \delta$ with the change in frequency and decay and return voltage slopes using extended voltage response method. The non-destructive diagnostic methods used are based on the phenomenon of polarization and conduction in the insulation material. The noteworthy change in the values of the imaginary part of permittivity, $\tan \delta$ at low frequencies, and the overall decrease in the values of return voltage slope showed the change in the structure of the polymer matrix under the stress which was related to the cross-linking based chemical reactions. The results show that the techniques can be adopted for the on-line condition monitoring of the cable for the PV system and the dielectric parameters can be used to study the chemical and physical changes happening inside the material effectively.
\end{abstract}

Keywords Photovoltaic power system $\cdot$ Low voltage DC cables $\cdot$ Thermal stress $\cdot$ Complex permittivity $\cdot$ Extended voltage response

\section{Introduction}

The share of renewable energy in the over-all world electricity consumption is rapidly growing due to its clean, green and reusable characteristics [1]. The photovoltaic (PV) system is one such renewable energy source out of other available sources which has been recognized as a cost-competitive, safe, environment-friendly, and reliable source of energy. It has been predicted that $\mathrm{PV}$ will surpass its competitor wind in new installed capacity in the coming years as a result

Ehtasham Mustafa

mustafa.ehtasham@vet.bme.hu

1 Department of Electric Power Engineering, Budapest University of Technology \& Economics, 18 Egry Joszef Street, 1111 Budapest, Hungary

2 Department of Electrical Power and Machines Engineering, Helwan University, 1 Sherif Street, Helwan, Cairo 11792, Egypt of huge price declines in recent times [2-4]. With more $\mathrm{PV}$ installation and usage, the knowledge and experience with this system have also increased [5]. This results in the observation and reporting of such faults which occur very occasionally, one such rare case is the failure of DC cable insulation [6].

In a PV system the four main components are to be connected, PV modules, the charge controller, the batteries and the inverter [4]. DC cables are used to connect the PV module and the inverter; converts the DC power into AC power which is the most important one and as the most popular form of electricity accepted in appliances. Although the DC cables account for only $2 \%$ in the solar project cost but they have a significant impact on the power output [7]. The PV modules and the DC cables are vulnerable to several extreme environmental conditions such as hot and cold temperatures, humidity, UV radiation, and wind [8]. In addition to the environmental stress, the DC cables also have to bear the mechanical and electrical stresses such as bending and 
voltage drop heating, respectively. Since the insulation of the cables is a polymer in nature, so the temperature stress and the voltage drop heating; combined as thermal stress affects the structure of the polymer $[9,10]$. This degradation phenomenon in cables is of more concerned than in other components of the PV systems as the thermal stress creates a chemical and physical alteration in the properties of the insulation. This may lead to safety hazards and reduced power output, in addition to the generation of leakage current which could end up in insulation failure and hence system failure. The cost of system shutdown combined with the cable replacement and repair is very high. Hence, this makes necessary to have the knowledge of the state and properties of the cable insulation and the mechanism of failure during operation. In this scenario, using the type of diagnostic method to study the cable insulation is imperative.

The change in the structure of the insulation material due to thermal stress results in a change in the chemical, mechanical and electrical characteristics of the material [11]. One way to study these changes happening inside the material is to use destructive chemical methods; density, ultrasonic velocity, thermogravimetric analysis (TGA), gel content, Fourier-transform infrared spectroscopy (FTIR), and oxidation induction time (OIT), and mechanical methods; elongation at break (EaB) and indenter modulus (IM) [12]. Due to destructive nature of the tests, their application for on-line condition monitoring has been limited. Since the primary purpose of the electrical insulation is its electrical integrity, so it is important to study the dielectric characteristics. The study of conduction and polarization phenomenon in the material is one such method that helps in understanding the changes happening inside the insulation material due to the thermal stress.

Cross-linked polyolefin (XLPO) has been widely used polymer in PV insulation DC cables due to a number of advantages such as thermal stability, dielectric properties, and solvent resistance. But XLPO has shown anomalous behavior during aging and has been reported in a number of literature [13-15]. The behavior of XLPO has been studied in these literature using destructive chemical and mechanical techniques. In this paper, the conduction and polarization phenomenon has been studied in view of the electrical properties of the complex permittivity $\left(\varepsilon^{*}\right)$, dissipation factor $(\tan \delta)$, decay voltage slope $\left(S_{d}\right)$ and return voltage slope $\left(S_{r}\right)$, being non-destructive methods. The phenomenon has been studied using component analyzer and extended voltage response (EVR) methods for thermally aged low voltage (LV) PV DC cables. Although a number of researchers have studied the electrical properties due to aging in LV cables [16-19] but none of them have studied the phenomenon for PV DC cables, which need due consideration for the safe and reliable operation of PV system. The prominent change in the values of $\tan \delta$, the imaginary part of permittivity $\left(\varepsilon^{\varepsilon}\right)$ and return voltage slopes $\left(S_{r}\right)$ proved that the applied methods are reliable and effective in studying the aging phenomenon in the PV DC cables without any damage to the cables, making them suitable for the on-line condition monitoring adopted for the PV system.

The paper has been organized as follows: the cable structure and characteristics, accelerated thermal aging, measurement of dielectric properties and EVR setup have been presented in Sect. 2. In Sect. 3, the results of the measurements have been laid out and a discussion on them in Sect. 4. While the conclusion and further prospects have been discussed in Sect. 5.

\section{Experimental Work}

\subsection{Materials}

The LV PV DC cable under investigation had the inner insulation and jacket composed of XLPO, Fig. 1a. The cable had a single-stranded copper conductor with tin plating
Fig. 1 a Low voltage power cable sample under investigation; b Air circulating oven for thermal aging

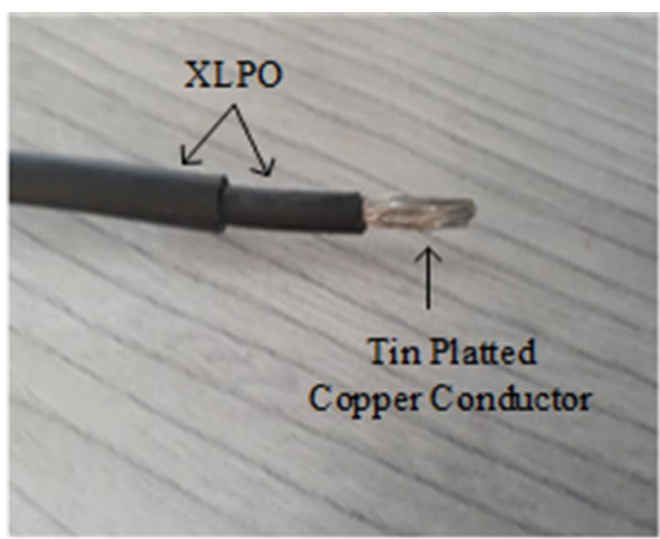

(a)

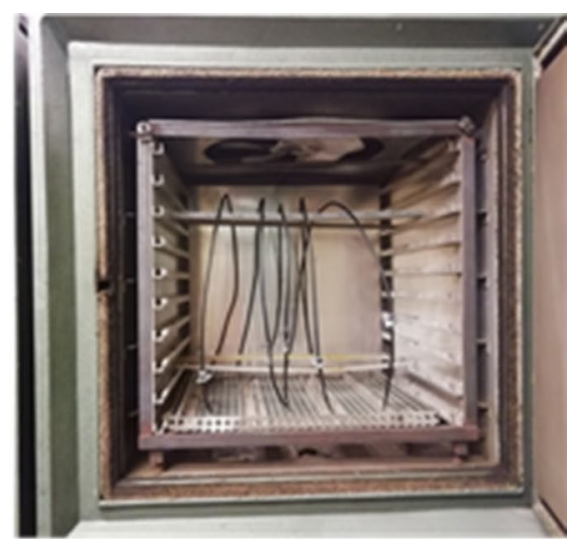

(b) 
(diameter $=2.25 \mathrm{~mm}$ ). The outer diameter of the cable was $5.8 \mathrm{~mm}$. A short length of the insulation was removed from the conductor and a short length of the jacket was removed from the insulation to prevent any leakage current to flow during measurements.

\subsection{Accelerated Aging}

The cable samples under consideration, one meter long were subjected to thermal stress at $120^{\circ} \mathrm{C}$ for four cycles; 240 , 480, 720 and $960 \mathrm{~h}$ in an air circulating oven, Fig. 1b. The thermal cycles were equivalent to $20,40,60$ and 80 years of service time at $60{ }^{\circ} \mathrm{C}$, which were based on the calculation using Arrhenius's relationship with taking the activation energy of $1.24 \mathrm{eV}$ into account. The jacket and the insulation were kept in contact with the conductor to obtain the results as the cable is subjected to the field conditions. After each thermal cycle, the samples were removed from the oven for analysis.

\subsection{Measurement of Dielectric Properties}

Precision Component Analyzer was used to study the dielectric properties, real $\left(\varepsilon^{\prime}\right)$ and imaginary $\left(\varepsilon^{\prime \prime}\right)$ part of complex permittivity and dielectric loss $(\tan \delta)$. The impedance and $\tan \delta$ of the cable samples were measured with an R-C parallel configuration setup for a frequency range of $20 \mathrm{~Hz}$ to $500 \mathrm{kHz}$ at an applied voltage of $5 \mathrm{~V}_{\mathrm{rms}}$ and at a room temperature of $25^{\circ} \mathrm{C} \pm 2 \%$. The input signal was applied to the conductor and the output signal was measured from a wire braid positioned on the outer surface of the cable. The cable samples and the electrodes were placed in the Faraday cage to reduce any pickup from the external noises.

The real permittivity $\left(\varepsilon^{\prime}\right)$ is a measure of how the external field energy is amassed within a material while how the material dissipates the energy from the external field is defined by the imaginary part of permittivity $\left(\varepsilon^{\prime \prime}\right)$ [20-23]. The real and imaginary part of the complex permittivity were evaluated from the measured data using the expressions [24]:

$\varepsilon^{\prime}=\frac{C(\omega)}{C_{o}}$

$\varepsilon^{\prime \prime}=\frac{1}{2 \pi f R C_{o}}$

where $C_{o}$ is the reference capacitance and is calculated by the known dimensions of the cable and the electrodes, while $f$ being the particular frequency during measurement.

The $\tan \delta$ is defined as the ratio of the imaginary part of permittivity $\left(\varepsilon^{\prime \prime}\right)$ to the real part of permittivity $\varepsilon^{\prime}$. Whenever a dielectric is subjected to an electric field, there are a number of losses; conduction, polarization, and partial discharge losses [25]. The first two losses are developed at a low electric field while the partial discharge losses happen at a high electric field. The conduction phenomenon is due to the transportation of the mobile charge carriers while the polarization is a complex phenomenon, which results due to several elementary processes. The measurement of $\tan \delta$ at the low electric field, as in our case, is very effective in studying the phenomenon of conduction and polarization in the material.

\subsection{Extended Voltage Response}

Whenever a structural change happens in the polymer matrix due to aging, it alters the dielectric property of the material. This change can be detected by studying the dielectric polarization phenomenon inside the material by applying a number of techniques classified based on frequency-domain and time-domain methods. One such time-domain method is the Extended Voltage Response (EVR) method. The method is very effective for studying those dielectric polarization processes which have high relaxation time constant or happening at a very low frequency such as the bulk, interfacial and hopping polarization processes. The EVR method is an extended version of the voltage response method and in recent times it has been implemented successfully to study the phenomenon in LV cables used in nuclear power plants, distribution systems and in high voltage cables and transformer insulations [26-30].

The basic working operation of the EVR measurement is shown in Fig. 2a. The insulation material is first charged at a DC voltage of $1000 \mathrm{~V}$ for $4000 \mathrm{~s}$. After the charging period, the material is discharged for 20 discharging periods i.e., from 1 to 2000s, which gives a wide range of slow polarization spectrum, Fig. 2b. From the method two voltage slopes; decay $\left(S_{d}\right)$ and return $\left(S_{r}\right)$ voltage slopes are measured, which is calculated by the two equations [31]:

$S_{d}=\left(V_{c h} / \epsilon_{\infty}\right) \gamma$

$S_{r}=\left(V_{c h} / \epsilon_{\infty}\right) \beta$

The decay voltage slope $\left(S_{d}\right)$ is generated when the charges on the electrodes are discharged in the insulation after the separation of the insulation from the voltage source and is directly related to the specific conductivity $(\gamma)$ of the insulation. While the return voltage slope $\left(S_{r}\right)$ is related to the polarization conductivity $(\beta)$ and is produced after a short discharging period, as a result, the polarization processes which remained excited in the insulation start to relax.

For the LV PV DC cable, the voltage was applied between the conductor and the outer surface of the cable, Fig. 3. All the measurements were carried out at a temperature of 25 

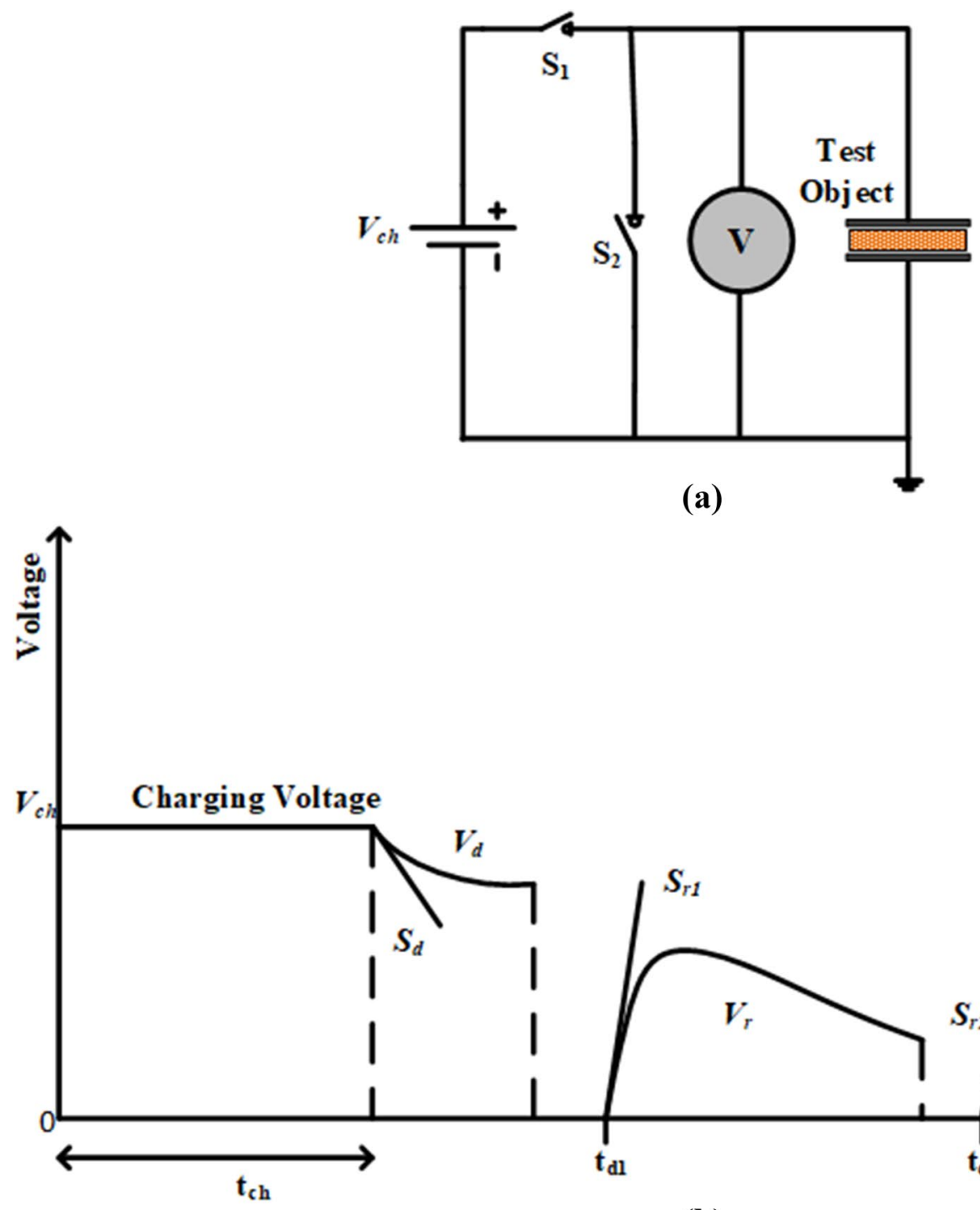

(a)

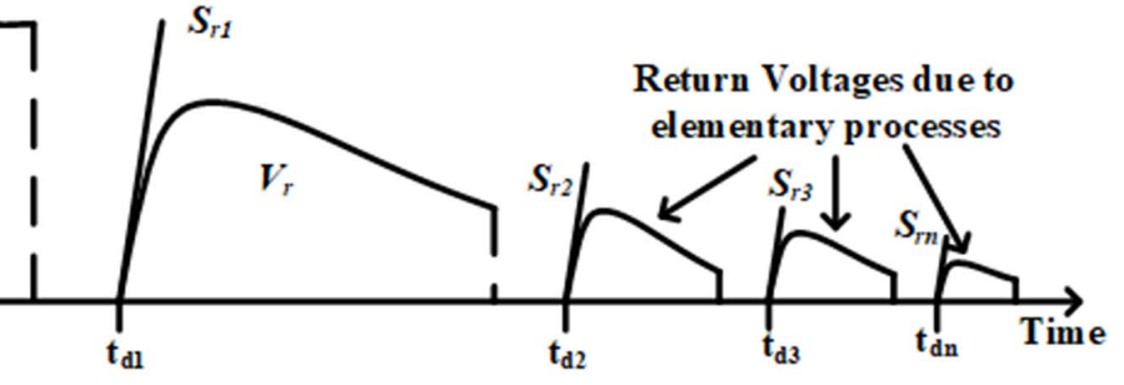

(b)

Fig. 2 Extended voltage response a Circuit; b Timing diagram

${ }^{\circ} \mathrm{C} \pm 2 \%$ and humidity of $25 \% \pm 2 \%$. After the EVR measurements, the cable samples were discharged for $5 \mathrm{~h}$ before the start of the next thermal cycle.

\section{Measurement Results}

\subsection{Dielectric Properties of Unaged and Aged Cable Samples}

Figure 4 shows the $\varepsilon^{\prime}$ of the unaged and aged cable samples. Irrespective of the aging, the $\varepsilon^{\prime}$ of the cable increased as the values of the frequency were shifted to lower values. The $\varepsilon^{\prime}$ decreased after the first thermal cycle at all frequencies. While an increase in the values of $\varepsilon^{\prime}$ was observed after the next three thermal cycles for the whole frequency range and became closer to the values of the unaged ones.

Figure 5a shows the $\varepsilon^{\prime \prime}$ of the PV cable for the range of frequency under consideration. The $\varepsilon^{\prime \prime}$ started from a higher value at high frequency and then moved to a minimum value with a decrease in the frequency. This behavior had been observed for both unaged and aged cable samples. The $\varepsilon^{\prime \prime}$ showed an interesting character with the change of frequency due to aging. After the first thermal cycle, a decreased in the values of $\varepsilon^{\prime \prime}$ was noted. An increase in the values of $\varepsilon^{\prime \prime}$ was observed between a frequency range of $200 \mathrm{~Hz}$ and $20 \mathrm{kHz}$ after the second thermal cycle. While at all other frequencies a decrease was detected. After the third thermal cycle, a decrease in the values of $\varepsilon^{\prime \prime}$ was noted at the frequency ranges of 20 to $200 \mathrm{~Hz}$ and $800 \mathrm{~Hz}$ to $5 \mathrm{kHz}$, whereas at all 
Fig. 3 Measurement setup of extended voltage response

Fig. 4 Relative permittivity $\left(\varepsilon^{\prime}\right)$ vs. Frequency for different aging times
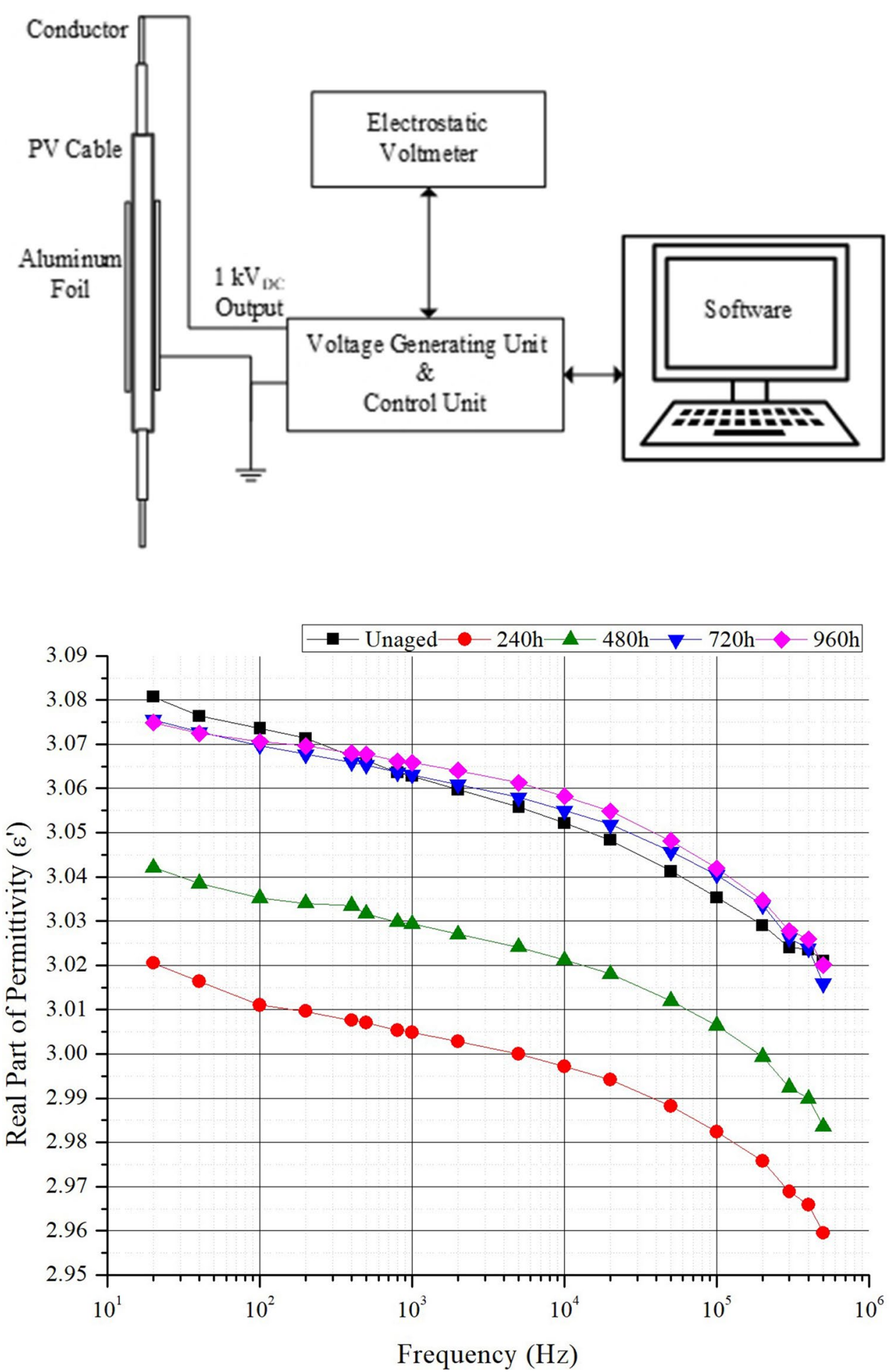

other frequencies, an increase was observed. At the end of the fourth thermal cycle, there was an increase between 5 and $500 \mathrm{kHz}$, though a decrease was observed between 20 $\mathrm{Hz}$ and $2 \mathrm{kHz}$ in the $\varepsilon^{\prime \prime}$.

For the briefness, four reference frequencies had been selected; $100 \mathrm{~Hz}, 200 \mathrm{~Hz}, 10 \mathrm{kHz}$, and $200 \mathrm{kHz}$, and plotted against the equivalent aging time in years, Fig. 5b. As can be observed that the $\varepsilon^{\prime \prime}$ values had decreased at low frequencies, i.e., $100 \mathrm{~Hz}$ and $200 \mathrm{~Hz}$ as compared to high frequencies.

The $\tan \delta$ of the unaged and aged cable is shown in Fig. 6a. There was a decrease of $\tan \delta$ as the frequency was decreased, starting from a maximum value and after reaching a minimum value at a certain frequency, there was an increase again in the $\tan \delta$. This variation of the $\tan \delta$ with 
Fig. 5 a Imaginary permittivity $\left(\varepsilon^{\prime \prime}\right)$ vs. Frequency with different aging time; $\mathbf{b} \varepsilon^{\prime \prime}$ vs. Equivalent Aging Time (Years) at $100 \mathrm{~Hz}, 200 \mathrm{~Hz}, 10 \mathrm{kHz}$, and $200 \mathrm{kHz}$

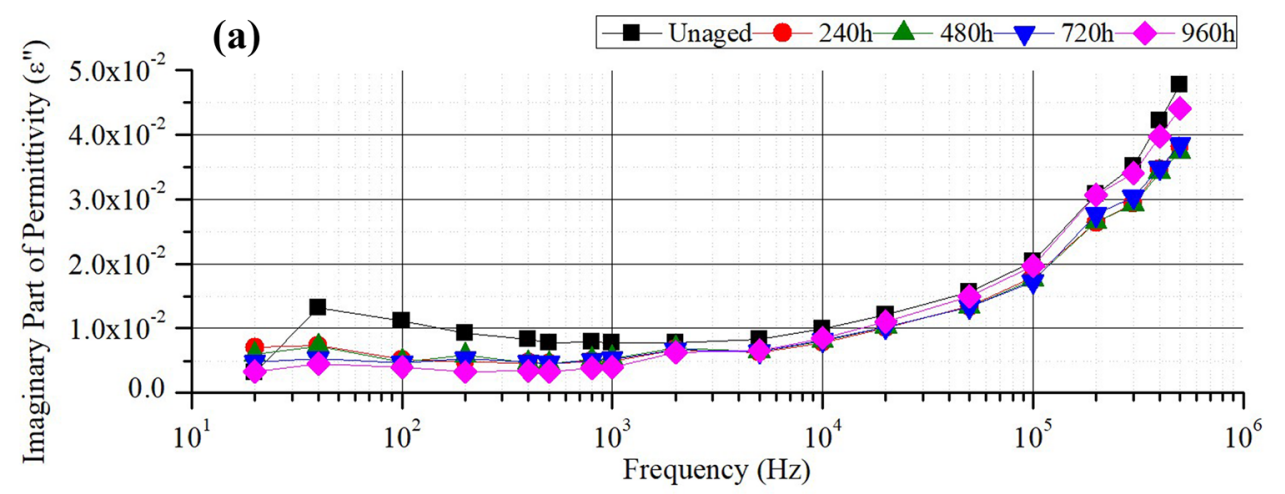

(b)

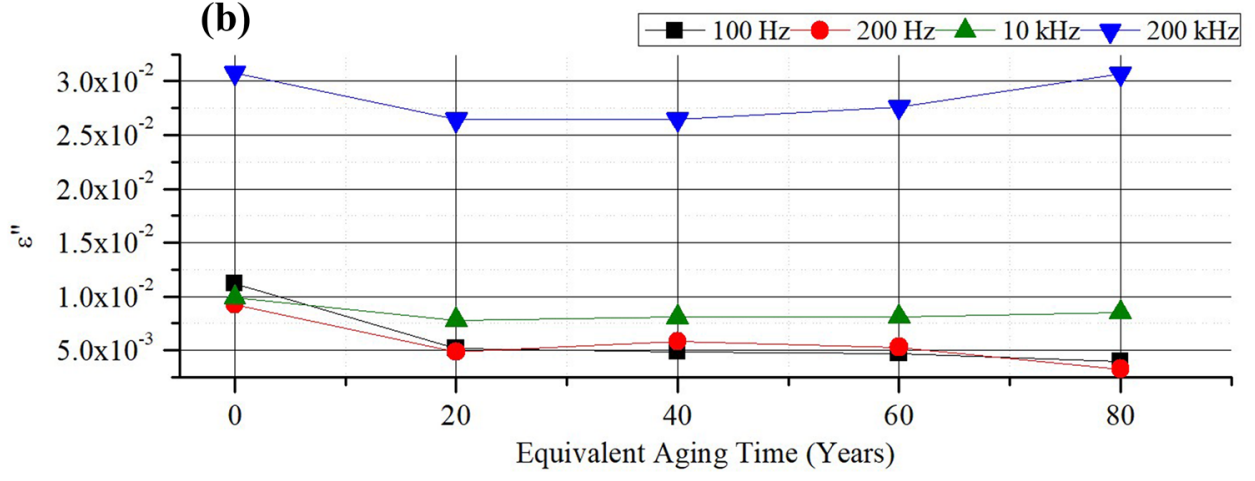

frequency was also irrespective of the aging cycle. Similar to $\varepsilon^{\prime \prime}$, the effect of aging on the $\tan \delta$ values was also very interesting. After the first thermal cycle, there was an overall decrease in the $\tan \delta$ for the whole range of frequency. While, after the second thermal cycle, at the frequency range of $500 \mathrm{~Hz}$ to $20 \mathrm{kHz}$, there was an increase in the values of $\tan \delta$. Whereas for a range of 20 to $400 \mathrm{~Hz}$ and $50 \mathrm{kHz}$ to $500 \mathrm{kHz}$ there was a decrease in the values. After the third and the fourth thermal cycle, a decrease in the values of $\tan \delta$ had been observed for the frequency range of $20 \mathrm{~Hz}$ to $100 \mathrm{kHz}$ and $20 \mathrm{~Hz}$ to $5 \mathrm{kHz}$, respectively. Even though an increase in the values had been observed between 200 and $500 \mathrm{kHz}$ for the third and between 5 and $500 \mathrm{kHz}$ for the fourth thermal cycles. Figure $6 \mathrm{~b}$ reports the $\tan \delta$ at four reference frequencies; $100 \mathrm{~Hz}, 200 \mathrm{~Hz}, 10 \mathrm{kHz}$, and $200 \mathrm{kHz}$ against equivalent aging time, where a decrease in the values at low frequencies was noted with aging.

\subsection{EVR Measurements}

The results of the EVR are shown in Fig. 7a and b for $S_{d}$ and $S_{r}$ respectively. The values of $S_{d}$ increased after the first and second thermal cycle. While a decrease was observed after the third thermal cycle and then an increase after the fourth thermal cycle. The overall effect was an increase in the values of $S_{d}$. The $S_{r}$ for the different aging cycles are plotted against the discharging time. It was observed that with the increase of the thermal stress, the $S_{r}$ increased after the first and second thermal cycle. But after the third and the fourth thermal cycle, a decrease in the values of the $S_{r}$ had been observed. Overall, the effect of thermal stress was an increase in the values of $S_{r}$ in reference to the unaged sample values.

\section{Discussion}

\subsection{Dielectric Properties}

The polarization phenomenon inside the material has a strong relationship with the $\varepsilon^{\prime}$ [32]. Since there was no discrepancy in relation to the frequency for the $\varepsilon^{\prime}$ of unaged and aged samples, so the $\varepsilon^{\prime}$ is independent of the frequency. The initial decrease in the $\varepsilon^{\prime}$ is due to the creation of the space charges, as it decreases the value of the permittivity. The increase of the permittivity after each thermal cycle shows that the dipolar by-products have been created which are adding to the polarization of the material. This shows that the structural changes happen inside the material.

The results of the $\varepsilon^{\prime \prime}$ show the dependency of $\varepsilon^{\prime \prime}$ on the frequency. The change in the values of the $\varepsilon^{\prime \prime}$ with aging was more prominent at a low frequency than at the high frequencies, which depicts that at higher frequencies the dependence of $\varepsilon^{\prime \prime}$ on aging is almost insignificant, Fig. 8. The greater change of $\varepsilon^{\prime \prime}$ at the low frequency shows that due to the thermal stress there has been a strong effect on the polymer 

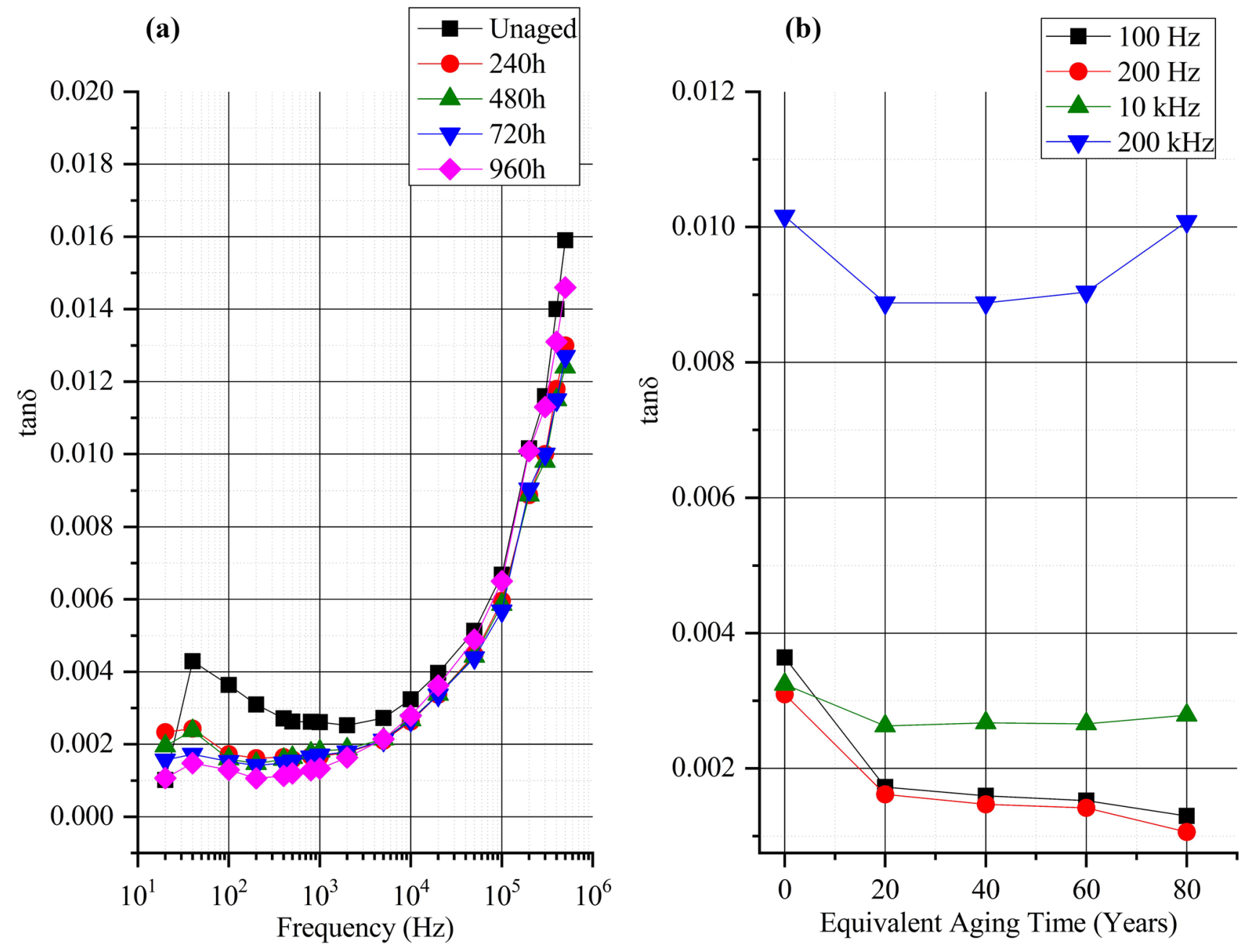

Fig. 6 a $\tan \delta$ vs. Frequency with different aging time; b tan $\delta$ vs. Equivalent Aging Time (Years) at $100 \mathrm{~Hz}, 200 \mathrm{~Hz}, 10 \mathrm{kHz}$, and $200 \mathrm{kHz}$

matrix. The creation of new bonds with a reduction of charge carriers is increasing with the thermal stress, as the change in the values of $\varepsilon^{\prime \prime}$ is increasing with each thermal cycle at the low frequency.

Since the $\tan \delta$ is considered to be composed of three main losses; conduction, polarization, and partial discharge losses. The variation of the $\tan \delta$ values is also quite large at the lower frequency than to the higher one, Fig. 9. The $\tan \delta$ values decreased with the aging cycle at a lower frequency, showing that the losses due to polarization and conduction charge particles have decreased with aging. This suggests the formation of cross-linking based chemical reactions, which is a three-dimensional network within the molecules and restricts the mobility of charge transportation. The values of $\tan \delta$ at different aging times with reference to values of unaged have been plotted, Fig. 9, against different aging times at three different frequencies, $100 \mathrm{~Hz}, 200 \mathrm{~Hz}$, and $400 \mathrm{~Hz}$, which clearly shows how the charge mobility has decreased with aging. The high change in the values of $\varepsilon^{\prime \prime}$ and $\tan \delta$ shows that the phenomenon contributing to the alteration to the dielectric property of the insulation material has reached to either conclusion or stabilization after 40-80 years.

\subsection{EVR}

As discussed for the dielectric properties results, the crosslinking reactions due to excessive thermal stress also results in the decrease of the interfacial polarization. The cross-linking reaction not only limits the charge movement but also restricts the dipole orientation, hence results in the decrease of polarization. This phenomenon has been associated with XLPO, as at elevated temperature the cross-linking occurs, which creates a kind of repair mechanism [10, 13, 14].

The increase in the $S_{d}$ values shows the increase in the specific conductivity of the material. The structural changes happening inside the material due to the thermal stress results in the production of localized sites for 
Fig. 7 EVR Measurements a $S_{d}$ vs. Aging time; b $S_{r}$ vs. Discharging time for different aging times

Fig. 8 The behavior of the imaginary part of permittivity at $100 \mathrm{~Hz}, 10 \mathrm{kHz}$, and $200 \mathrm{kHz}$ with reference to unaged values against Equivalent Aging Time in Years
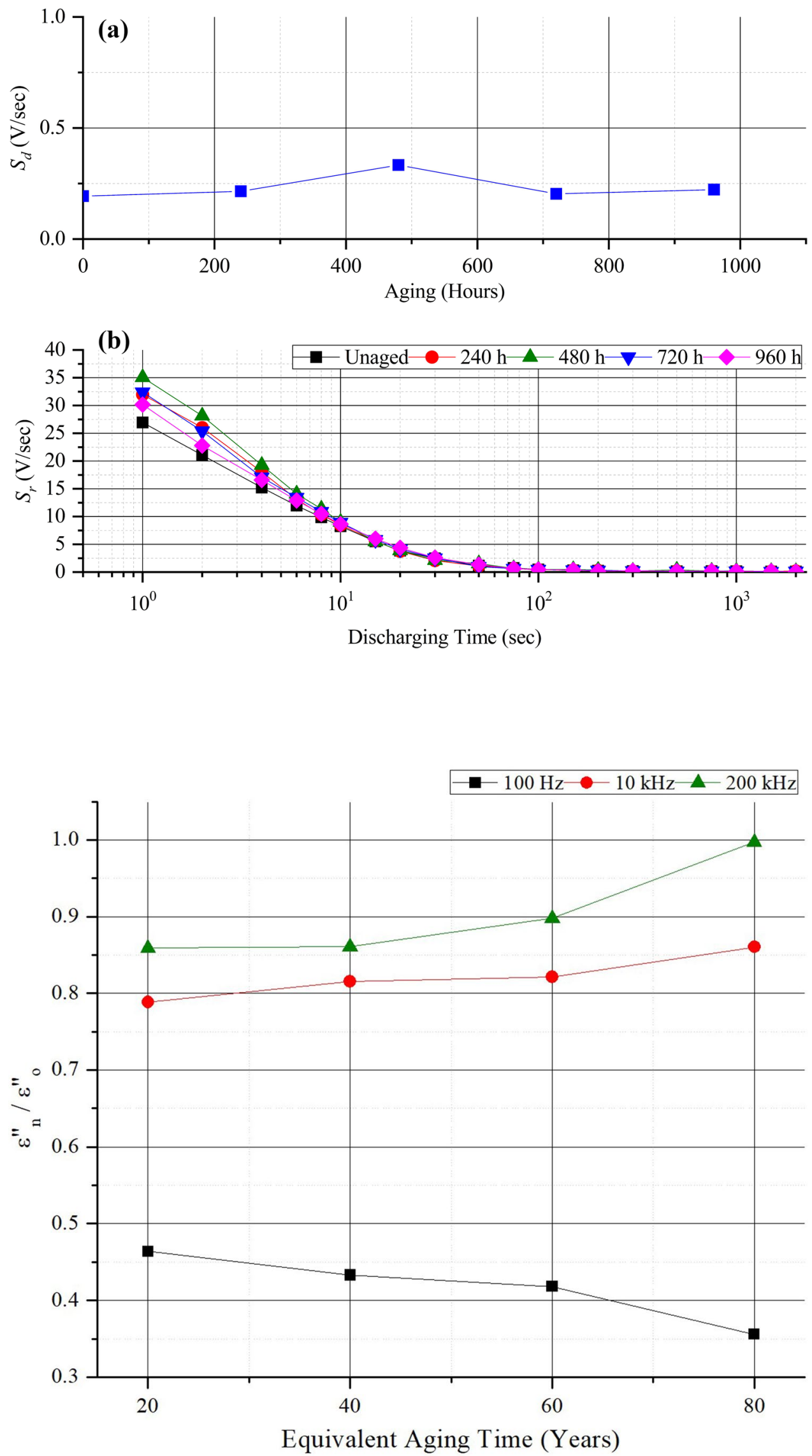
Fig. 9 The behavior of $\tan \delta$ at $100 \mathrm{~Hz}, 200 \mathrm{~Hz}$, and $400 \mathrm{~Hz}$ vs. Equivalent Aging Time in Years with reference to unaged values

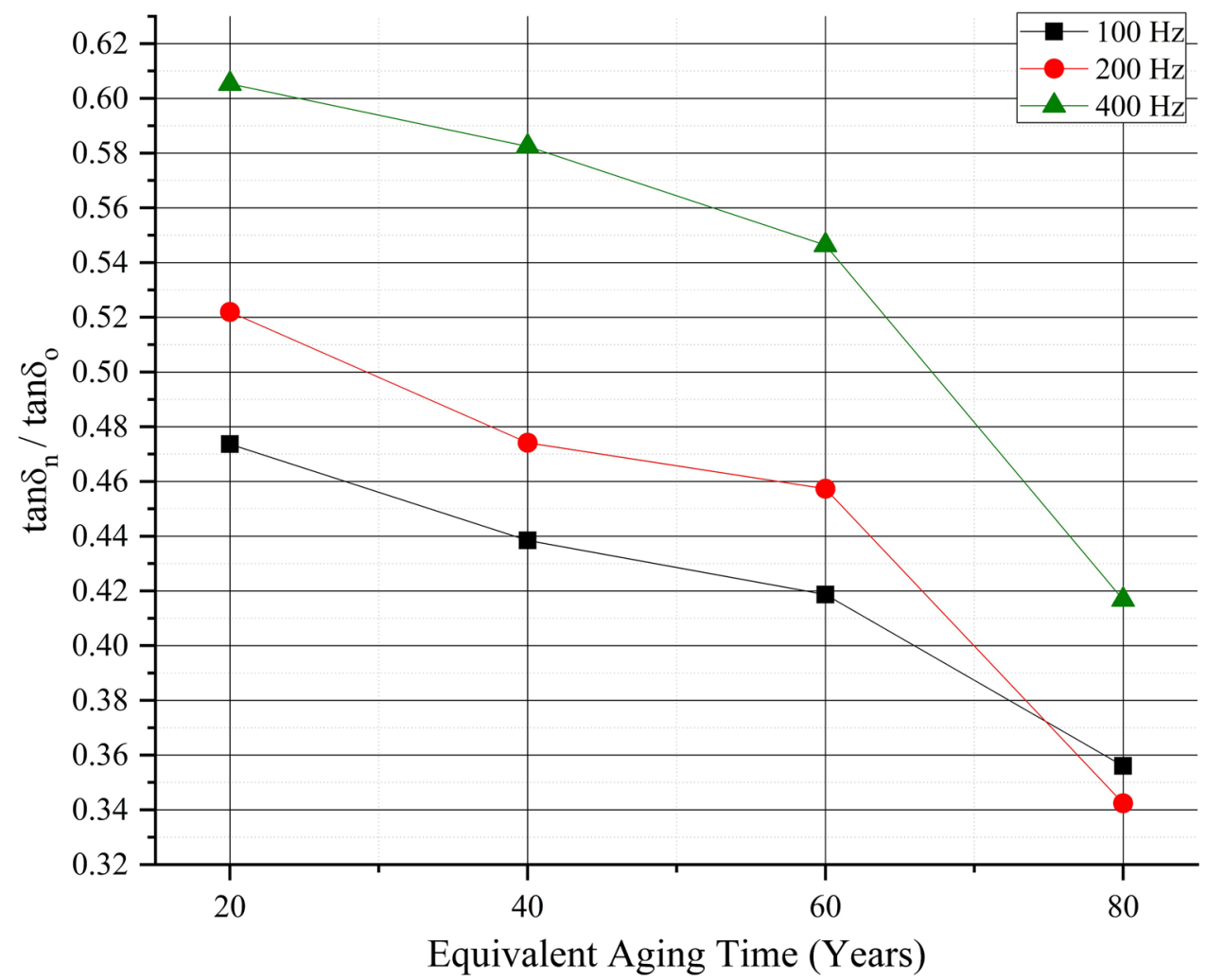

exposure for a long time at elevated temperature results in the decrease in the values of the $\varepsilon^{\prime \prime}, \tan \delta$, and $S_{r}$.

\section{Conclusions}

In this work, the effect of thermal stress on the XLPO based LV PV DC cables were analyzed. With component analyzer, the real $\left(\varepsilon^{\prime}\right)$ and imaginary part $\left(\varepsilon^{\prime \prime}\right)$ of permittivity and $\tan \delta$ for a wide range of frequency were measured and with the EVR, decay voltage $\left(S_{d}\right)$ and return voltage $\left(S_{r}\right)$ slopes were analyzed. It was observed that with the effect of thermal stress, the polymer matrix was altered and the species contributing to the conduction and polarization phenomenon were reduced with aging.

The results of $\varepsilon^{\prime \prime}$, tan $\delta$ and $S_{r}$ show that the thermallyinduced changes in XLPO were because of re-cross-linking reactions; as observable by the noticeable decrease in the values, a phenomenon associated with semi-crystalline materials when exposed to high temperatures. This resulted in a decrease in the interfacial and bulk polarization processes inside the material with the aging time. The $\tan \delta$ at $100 \mathrm{~Hz}$, the $\varepsilon^{\prime \prime}$ at $100 \mathrm{~Hz}$ and the $S_{r}$ showed good results of the state of the cable insulation, hence making them feasible to use as electrical aging markers for the assessement of the cable insulation condition. It can be speculated that these methods being non-destructive and simple can be used as

The phenomenon of the re-creation of cross-linking, which is observed in semi-crystalline materials due to 
diagnostic techniques effectively with the potential of being applied in the field for the online monitoring of the condition of the cables for the PV system, which is important for its reliability and safe operation. Also, this research work can be helpful in scaling-up the current cable qualification standard. For the future perspective, setting the threshold values of the aging markers the prediction of the remaining life of the PV cable can be evaluated in addition to the determination of the state of the cable.

Acknowledgements Open access funding provided by Budapest University of Technology and Economics (BME).

Open Access This article is licensed under a Creative Commons Attribution 4.0 International License, which permits use, sharing, adaptation, distribution and reproduction in any medium or format, as long as you give appropriate credit to the original author(s) and the source, provide a link to the Creative Commons licence, and indicate if changes were made. The images or other third party material in this article are included in the article's Creative Commons licence, unless indicated otherwise in a credit line to the material. If material is not included in the article's Creative Commons licence and your intended use is not permitted by statutory regulation or exceeds the permitted use, you will need to obtain permission directly from the copyright holder. To view a copy of this licence, visit http://creativecommons.org/licenses/by/4.0/.

\section{References}

1. E. Mustafa, R. S. A. Afia, Z. Á. Tamus, Lecture Notes in Electrical Engineering, ed. by B. Németh (Springer, Cham, 2020)

2. A. Jäger-Waldau, Energies (2019). https://doi.org/10.3390/en120 50769

3. International Renewable Energy Agency IRENA, Abu Dhabi, UAE (2018)

4. K. Vyas, Managing Solar Cables and Connectors For Safety and Longevity of PV System (New Delhi, India, 2017)

5. F. Schimpf, L. E. Norum, In 31st Int. Telecommun. Energy Conf., Incheon, Korea, (2009)

6. J. Packa, V. Kujan, D. Štrkula, V. Šály, M. Perný, Trans. Electr. Eng. 6, 6-9 (2017). https://doi.org/10.14311/TEE.2017.1.006

7. K. Padmanathan, U. Govindarajan, V.K. Ramachandaramurthy, S.O. Selvi, B. Jeevarathinam, J. Ind. Inf. Integr. (2018). https:// doi.org/10.1016/j.jii.2018.01.003

8. G. Parise, L. Martirano, IEEE Trans. Ind. Appl. 50(3), 2156-2163 (2014). https://doi.org/10.1109/TIA.2013.2283197

9. Z. Zhang, P.D.S. Assala, L. Wu, Electr. Power Syst. Res. 163, 572-580 (2018). https://doi.org/10.1016/j.epsr.2017.12.027

10. M. Celina, K.T. Gillen, J. Wise, R.L. Clough, Radiat. Phys. Chem. 48, 613-626 (1996). https://doi.org/10.1016/0969-806X(96)00083-7

11. A. Paramane, X. Chen, C. Dai, H. Guan, L. Yu, Y. Tanaka, Polym. Compos. (2020). https://doi.org/10.1002/pc.25509

12. International Atomic Energy Agency, IAEA (Austria, Vienna, 2017)

13. M. Celina, K. T. Gillen, R. L. Clough, Annealing Phenomena in the Radiation Degradation of Crosslinked Polyolefins
(IAEA-TECDOC--1062), International Atomic Energy Agency (IAEA), (1999)

14. M. Celina, K.T. Gillen, R.L. Clough, Polym. Degrad. Stab. 61, 231-244 (1998). https://doi.org/10.1016/S0141-3910(97)00142-0

15. E. Mustafa, R. S. A. Afia, Z. Á. Tamus, In: 7th Int. Youth Conf. Energy, Bled, Slovenia (2019)

16. Z. Zhou, D. Zhang, J. He, M. Li, I.E.E.E. Trans, Dielectr. Electr. Insul. 22, 2097-2107 (2015). https://doi.org/10.1109/ TDEI.2015.004799

17. M. Ekelund, P.F. Fantoni, U.W. Gedde, Polym. Test 30, 86-93 (2011). https://doi.org/10.1016/j.polymertesting.2010.11.003

18. L. Verardi, D. Fabiani, G.C. Montanari, Radiat. Phys. Chem. 94, 166-170 (2014). https://doi.org/10.1016/j.radphysche m.2013.05.038

19. N. Bowler, S. Liu, Progn. Heal. Manag. Soc. pp. 1-12 (2015) https ://www.phmsociety.org/node/1638

20. S.Z.A. Dabbak, H.A. Illias, B.C. Ang, N.A.A. Latiff, M.Z.H. Makmud, Energies (2018). https://doi.org/10.3390/en11061448

21. N. Bashir, H. Ahmad, M. Shaffuan Suddin, In: IEEE 2010 Conf. Proc. IPEC., Singapore, Singapore, pp. 1062-1066 (2010)

22. C. D. Paraskevas, P. Vassiliou, C. T. Dervos, In: IEEE Int. Conf. Dielectr. Liq., Coimbra, Portugal, pp. 275-278 (2005)

23. S.Z. Dabbak, H.A. Illias, B.C. Ang, I.E.E.E. Trans, Dielectr. Electr. Insul. 24, 3758-3765 (2017). https://doi.org/10.1109/ TDEI.2017.006418

24. E. Barsoukov, J.R. Macdonald, Impedance Spectroscopy Theory, Experiment, and Applications (Wiley, New Jersey, 2010)

25. M. Farahani, H. Borsi, E. Gockenbach, Electr. Eng. 89, 263-270 (2007). https://doi.org/10.1007/s00202-006-0011-9

26. E. Mustafa, Á. Z. Tamus, R. S. A. Afia, IFIP Advances in Information and Communication Technology, ed. by L. Camarinha-Matos, R. Almeida, J. Oliveira (Springer, Cham, 2019), p. 405 https://doi. org/10.1007/978-3-030-17771-3_35

27. E. Mustafa, R.S.A. Afia, Á.Z. Tamus, In: 2018 Int. Conf. Diagn. Electr. Eng, Pilsen, Czech Republic, pp. 69-72 (2018)

28. Z. Á. Tamus, G. M. Csányi, Á. Szirmai, A. Nagy, In: Int. Sci. Symp. Electr. Power Eng., Varna, Bulgaria, pp. 7-13 (2016)

29. G. M. Csányi, Z. Á. Tamus, In: 2017 6th Int. Youth Conf. Energy, Budapest, Hungary, pp. 2-5 (2017) https://doi.org/10.1109/ IYCE.2017.8003702

30. Á. Z. Tamus, Á. Szirmai, B. Németh, In: The 19th Int. Symp. High Volt. Eng., Pilsen, Czech Republic (2015)

31. E. Nemeth, IEE Proc- Sci. Meas. Technol. 146(5), 249-252 (1999). https://doi.org/10.1049/ip-smt:19990651

32. X. Chen, A. Paramane, H. Liu, J. Tie, Z. Wei, Y. Tanaka, Polym. Eng. Sci (2020). https://doi.org/10.1002/pen.25330

33. S. Morsalin, T.B. Phung, M. Danikas, D. Mawad, IET Sci. Meas. Technol. 13(6), 767-782 (2019). https://doi.org/10.1049/ iet-smt.2018.5597

34. D. Min, C. Yan, Y. Huang, S. Li, Y. Ohki, Polym. (Basel) 9, 1-15 (2017). https://doi.org/10.3390/polym9100533

Publisher's Note Springer Nature remains neutral with regard to jurisdictional claims in published maps and institutional affiliations. 